\title{
Educação escolar e direitos indígenas: uma revisão integrativa de teses e dissertações a partir do BDTD
}

\author{
School education and indigenous rights: an integrative review of theses and \\ dissertations from the BDTD
}

\section{Educación escolar y derechos indígenas: uma revisión integrativa de tesis y disertaciones a partir del BDTD}

\author{
Cláudio Emidio Silva* \\ Lucas Antunes Furtado ${ }^{* *}$
}

\section{Resumo}

Este estudo aborda a relação entre a educação escolar e os direitos indígenas no Brasil. Tem como objetivo analisar e sintetizar as teses e dissertações que versam sobre as categorias: educação escolar e direitos indígenas. Caracteriza-se como uma revisão integrativa, utilizando como base bibliográfica teses e dissertações do Banco de Dados de Teses e Dissertações do Instituto Brasileiro de Informação em Ciência e Tecnologia. Foram selecionadas doze pesquisas no período de 2008 a 2018, totalizando 10 anos de recorte temporal. Os resultados apresentam análises interpretativas sobre o modo como as pesquisas abordam as categorias de análise. O estudo está estruturado da seguinte forma: primeiramente, explica-se a abordagem metodológica, a revisão integrativa e seus processos. No segundo momento, apresentam-se os resultados do levantamento das teses e dissertações, seguidos das análises e sínteses dos estudos selecionados. Por último, constam as considerações finais.

Palavras-chave: Direitos humanos. Direitos indígenas. Educação escolar.

\section{Abstract}

The study addresses the relationship between school education and indigenous rights in Brazil. Its objective is to analyze and synthesize the theses and dissertations that deal with the categories: school education and indigenous rights. It is characterized as an Integrative Revision, using as bibliographic basis theses and dissertations of the Database of Theses and Dissertations, of the Brazilian Institute of Information in Science and Technology. Twelve researches were selected in the period from 2008 to 2018, adding up to 10 years of time cut. The results

Recebido em 08/04/2019 - Aprovado em 01/07/2019

http://dx.doi.org/10.5335/rep.v26i3.9309

Doutor em Educação pelo Programa de Pós-Graduação em Educação da Universidade Federal do Pará (UFPA). Professor de Prática e Metodologia do Ensino de Ciências, Biologia e Química no Instituto de Ciências Naturais da Universidade Federal do Sul e Sudeste do Pará (UNIFESSPA). Brasil. ORCID: 0000-0001-8769-5383. E-mail: emidiosilva@yahoo. com.br

** Doutorando em Educação no Programa de Pós-Graduação em Educação da Universidade Federal do Pará (UFPA). Professor de Sociologia e Antropologia da Educação na Faculdade de Educação da Universidade Federal do Amazonas (UFAM). Brasil. ORCID: 0000-0001-5782-7584. E-mail: lucasfurtado@ufam.edu.br 
present interpretive analyzes on the way in which the surveys approach the categories of analysis. The study is structured as follows: firstly, the methodological approach, integrative review and its processes are explained. In the second moment, the results of the theses and dissertations are presented, followed by the analyzes and syntheses of the selected studies. Finally, the final considerations.

Keywords: Human rights. Indigenous rights. Schooling.

\section{Resumen}

El estudio plantea la relación entre educación escolar y los derechos de los indígenas en Brasil. Tiene como objetivo analizar y sintetizar las tesis y disertaciones que tratan de las categorías: educación escolas y derechos indígenas. Se caracteriza como una Revisión Integrativa, utilizando como base bibliográfica tesis y disertaciones del Banco de Datos de Tesis y Disertaciones, del Instituto Brasileiro de Informação em Ciência e Tecnologia. Se seleccionaron doce investigaciones en el periodo de 2008 a 2018, totalizando 10 años de recorte temporal. Los resultados presentan análisis interpretativas sobre la forma como las investigaciones abordan las categorías de análisis. El estudio se estructura de siguiente forma: en primero lugar, se explica el abordaje metodológico, revisión integrativa y sus procesos. En un segundo lugar, se presentan los resultados de la recopilación de las tesis y disertaciones, seguida de los análisis y síntesis de los estudios seleccionados. Por último, las consideraciones finales.

Palabras-clave: Derechos humanos. Derechos indígenas. Educación escolar.

\section{Introdução}

O projeto de escola imposto aos povos indígenas é contemporâneo ao processo de colonização europeia, tendo como marco temporal a invasão das Américas a partir de 1492. O projeto de escolarização foi orquestrado para controlá-los e dominá-los, pois o modelo de escola eurocêntrica encobria e marginalizava os elementos socioculturais, objetivando o embranquecimento contínuo dos povos tradicionais.

O processo de escolarização dos povos indígenas foi pensado e operacionalizado por missionários jesuítas, em sua maioria a mando da Coroa Portuguesa, que instituiu a educação eurocêntrica aos indígenas a partir de instrumentos oficiais como Cartas Régias e Regimentos. O controle da educação para os indígenas foi regido pelos missionários no período compreendido entre os séculos XVI e XVIII. Em outras palavras, foram 200 anos de embranquecimento a partir de processos educativos cristocêntricos, patriarcais e coloniais, forçando os indígenas a "esquecerem" suas culturas, substituindo-as pela cultura do colonizador, seus hábitos e seus costumes, deixando até de falarem suas próprias línguas, substituindo-as pelo português. Tudo isso para que o indígena deixasse de ser indígena, alinhando-se aos interesses do colonizador. 
A partir do século XVIII, a Coroa Portuguesa começa a redimensionar a responsabilidade de instruir os "gentios". Aos poucos, outros sujeitos leigos foram conduzidos a ombrear os processos educativos, que, mesmo na ausência dos jesuítas, continuavam com as chagas cristocêntricas no ato de "educar". A conversão e o embranquecimento dos indígenas continuaram sendo o objetivo central das escolas.

Nos idos do século XIX, no Brasil Império, a herança perversa da educação eurocêntrica foi mantida e consolidada. Após a Declaração da Independência, em 07 de setembro de 1822, foram elaborados Projetos Constitucionais que propunham a criação de "estabelecimentos para a Catechese e civilização dos índios" (LUCIANO, 2007, p. 04). Em 1845, a partir do Decreto 246, atribui-se às Assembleias Provinciais a competência de promover junto aos governos gerais as missões de catequese e civilização dos índios. Desta forma, a questão da educação dos povos indígenas se manteve até o início da primeira república, em 15 de novembro de 1889.

$\mathrm{Na}$ primeira república, as questões dos povos indígenas, sobretudo a escolarização, foram redimensionadas ao Ministério da Agricultura, Pecuária e Abastecimento (Mapa) e, em 1910, foi criado o Serviço de Proteção ao Índio (SPI), órgão ligado ao Mapa e destinado exclusivamente às questões dos povos tradicionais. Como consequência desse novo cenário jurídico-administrativo, ampliou-se o processo de implementação dos projetos de escolas "indígenas", visando reprimir o trânsito dos aldeados para outras regiões, principalmente para os grandes centros urbanos, ou seja, objetivava-se a sedentarização dos povos tradicionais a partir da alfabetização das crianças e dos adultos.

Com a promulgação da Constituição federal de 1934 (CF/34) (BRASIL, 1934), a questão dos povos originários fora atribuída ao poder exclusivo da União. A referida Constituição estabeleceu a competência da União para legislar sobre o processo de "incorporação dos silvícolas à comunhão nacional" (BRASIL, 1934), princípio esse reiterado nas Constituições posteriores, a exemplo das de 1946 e 1967 (BRASIL, 1946, 1967). A partir de então, 66 escolas "indígenas" foram organizadas pelo SPI até a sua extinção em 1967. Essas escolas, junto aos projetos de escolarização de missionários, passaram a representar instrumento institucional para cumprir com a "civilização" dos indígenas, uma vez "incorporados" à sociedade envolvente. Esse processo foi fortemente marcado pela característica da negação das diferenças socioculturais e pelo assimilacionismo nacional, até porque as supostas escolas "indígenas” reproduziam currículos das escolas rurais, voltadas para a alfabetização em português e o ensino de ofícios como corte e costura, marcenaria, culinária, entre outros. 
Em paralelo com a realidade da questão indigenista no Brasil, em 1951, ocorreu a 6 6 $^{\text {a }}$ Conferência Geral das Nações Unidas para a Educação, a Ciência e a Cultura (UNESCO), surgindo as primeiras propostas para implementação de uma educação bilíngue para os povos tradicionais. No entanto, tais orientações foram consideradas inadequadas à realidade brasileira pelos técnicos do SPI. "Um dos argumentos mais significativo era de que programas de educação bilíngue poderiam colidir com os valores da incorporação dos índios à comunhão nacional" (LUCIANO, 2007, p. 04). Não obstante, em 1957, ocorreu a Convenção no 107 da Organização Internacional do Trabalho (OIT), que tratou sobre a proteção e integração dos indígenas dos países independentes, sendo ratificada e incorporada no Brasil anos depois. Salienta-se que as orientações da UNESCO, de 1951, e da OIT/107, de 1957, não discutiram aspectos de uma educação aberta às realidades socioculturais específicas dos povos originários. Considera-se, então, que a ideia da educação bilíngue fosse meramente técnica, instrumental, sem interesses na valorização cultural dos povos tradicionais.

A escolarização dos povos indígenas, até a década de 1960, foi utilizada como um instrumento perverso para desestruturar, desarticular e controlar os povos tradicionais, a fim de "ajustá-los" aos interesses do "desenvolvimento" nacional. No entanto, os indígenas, desde o início das invasões, em 1492, sempre se colocaram como resistentes ao processo de colonização. No que se refere à educação escolar indígena, a partir da década de 1970 houve um giro na condução da questão. A escola tornou-se um espaço tático de pós-contato, objetivando a preparação dos povos para ampliação das relações com a sociedade envolvente, assim, o sentido de escola foi ressignificado. Nas mãos dos próprios indígenas, a escola passou a ser mais uma estratégia para contribuir com a autonomia e a afirmação identitária. Portanto, a escola foi/é vista como uma das possibilidades para decifrar o "mundo" do não indígena, e esse giro foi/é mais uma forma de resistência dos povos tradicionais.

Entretanto, é preciso salientar que a mudança não foi total nem de uma hora para outra. Assim, as duas formas de conceber as escolas indígenas passaram a coexistir, havendo tanto escolas ressignificadas quantos outras, que reproduziam a escola do colonizador. Atualmente as escolas indígenas, na concepção de uma educação escolar indígena a partir da Constituição federal de 1988 (CF/88) e das leis subsequentes que tratam da educação, lutam por direitos alcançados para que exista realmente uma educação intercultural, bilíngue/multilíngue, comunitária, diferenciada e específica, o que ainda se constitui em um grande desafio, que mui- 
tas estão superando, mas outras se encontram no processo de luta, reestruturação e, ainda, ressignificação.

Nesse sentido, tem-se o caso do movimento dos professores indígenas dos estados Amazonas, Roraima e Acre, iniciando os encontros no ano de 1988 e finalizando em 1997, ou seja, foram 10 anos de reflexões e proposições sobre os processos socioeducativos dos povos indígenas. ${ }^{1}$ Esse movimento tornou-se referência nacional, pois as discussões giravam em torno das especificidades da questão da educação escolar indígena, discutindo sobre as condições objetivas para a formulação de políticas públicas sensíveis às realidades concretas dos indígenas no Brasil (LUCIANO, 2007; SILVA, 1999).

Após duas décadas, o Estado, através da promulgação da CF/88, incorporou as questões reivindicadas pelos movimentos indígenas. O Estado foi forçado, por pressão pública nacional e internacional, a reconhecer os avanços e as conquistas das experiências dos povos indígenas. As experiências dos povos tradicionais sempre se caracterizaram como um contraponto aos projetos colonialistas que tendiam a homogeneizá-los e integrá-los à sociedade nacional. Em termos conceituais, jurídicos e políticos, a CF/88 é um marco para as políticas indigenistas oficiais. Segundo Luciano (2007, p. 05):

A CF/88 superou de forma definitiva a concepção absolutamente equivocada da incapacidade indígena que fundamentou o princípio jurídico da Tutela, [...] explicitando a garantia dos direitos dos povos indígenas ao reconhecer suas culturas, tradições, línguas, organizações sociais, crenças, enfim, o direito de continuarem vivendo segundo suas culturas e suas livres escolhas.

À vista disto, a lógica e as práticas coloniais ainda persistem nos âmbitos cultural e político, porém, avançou-se nos campos teórico e legal. Como consequência, houve outras conquistas constitucionais com o foco na garantia e efetividade dos direitos dos povos indígenas. Isso posto, destacam-se os principais marcos regulatórios que orientam a implementação das escolas indígenas no Brasil atualmente. 
Quadro 1 - Principais marcos regulatórios para a educação escolar indígena - Belém, 2018

\begin{tabular}{|c|c|c|c|c|}
\hline $\begin{array}{l}\text { Constitui- } \\
\text { ção federal } \\
\text { de } 1988\end{array}$ & $\begin{array}{l}\text { Art. } 210 \text { - Serão fixados } \\
\text { conteúdos mínimos para o } \\
\text { ensino fundamental, de ma- } \\
\text { neira a assegurar formação } \\
\text { básica comum e respeito } \\
\text { aos valores culturais e artís- } \\
\text { ticos, nacionais e regionais. }\end{array}$ & $\begin{array}{l}\text { Art. } 215 \text { - O Estado garanti- } \\
\text { rá a todos o pleno exercício } \\
\text { dos direitos culturais popu- } \\
\text { lares e acesso às fontes da } \\
\text { cultura nacional, e apoiará e } \\
\text { incentivará a valorização e a } \\
\text { difusão das manifestações } \\
\text { culturais. }\end{array}$ & $\begin{array}{l}\text { Art. } 231 \text { - São reconheci- } \\
\text { dos aos índios sua orga- } \\
\text { nização social, costumes, } \\
\text { línguas, crenças e tradi- } \\
\text { ções, e os direitos origi- } \\
\text { nários sobre as terras que } \\
\text { tradicionalmente ocupam, } \\
\text { competindo à União demar- } \\
\text { cá-las, proteger e fazer res- } \\
\text { peitar todos os seus bens. }\end{array}$ & $\begin{array}{l}\text { Art. } 232 \text { - Os índios, suas co- } \\
\text { munidades e organizações são } \\
\text { partes legítimas para ingressar } \\
\text { em juizo em defesa de seus di- } \\
\text { reitos e interesses, intervindo o } \\
\text { Ministério Público em todos os } \\
\text { atos do processo. }\end{array}$ \\
\hline $\begin{array}{l}\text { Lei } n^{0} 9.394 \\
\text { de } 1996\end{array}$ & $\begin{array}{l}\text { Art. } 32 \text { - } 0 \text { ensino funda- } \\
\text { mental regular será minis- } \\
\text { trado em língua portuguesa, } \\
\text { assegurada às comunida- } \\
\text { des indígenas a utilização } \\
\text { de suas línguas maternas } \\
\text { e processos próprios de } \\
\text { aprendizagem. }\end{array}$ & $\begin{array}{l}\text { Art. } 78 \text { - O Sistema de Ensi- } \\
\text { no da União, com a colabora- } \\
\text { ção das agências federais de } \\
\text { fomento à cultura e de assis- } \\
\text { tência aos índios, desenvol- } \\
\text { verá programas integrados } \\
\text { de ensino e pesquisa, para } \\
\text { oferta de educação escolar } \\
\text { bilíngue e intercultural aos } \\
\text { povos indígenas. }\end{array}$ & $\begin{array}{l}\text { Art. } 79 \text { - A União apoiará } \\
\text { técnica e financeiramente } \\
\text { os sistemas de ensino no } \\
\text { provimento da educação } \\
\text { intercultural às comunida- } \\
\text { des indígenas, desenvol- } \\
\text { vendo programas integra- } \\
\text { dos de ensino e pesquisa. }\end{array}$ & \\
\hline $\begin{array}{l}\text { Plano } \\
\text { Nacional de } \\
\text { Educação } \\
- \text { Lei } n^{0} \\
10.172 \text { de } \\
2001\end{array}$ & $\begin{array}{l}\text { 1. Atribuir aos Estados a } \\
\text { responsabilidade legal pela } \\
\text { educação indígena quer di- } \\
\text { retamente, quer através de } \\
\text { delegação de responsabili- } \\
\text { dades aos seus municípios, } \\
\text { sob a coordenação geral e } \\
\text { com o apoio financeiro do } \\
\text { Ministério da Educação. }\end{array}$ & $\begin{array}{l}\text { 2. Universalizar imediata- } \\
\text { mente a adoção das dire- } \\
\text { trizes para a política nacio- } \\
\text { nal de educação escolar } \\
\text { indígena e os parâmetros } \\
\text { curriculares estabelecidos } \\
\text { pelo Conselho Nacional de } \\
\text { Educação e pelo Ministério } \\
\text { da Educação. }\end{array}$ & $\begin{array}{l}\text { 6. Criar, dentro de um ano, } \\
\text { a categoria oficial de "es- } \\
\text { cola indígena" para que a } \\
\text { especificidade do modelo } \\
\text { de educação intercultural } \\
\text { e bilíngue seja assegurada. }\end{array}$ & $\begin{array}{l}\text { 8. Assegurar a autonomia das } \\
\text { escolas indígenas, tanto no que } \\
\text { se refere ao projeto pedagógico } \\
\text { quanto ao uso de recursos fi- } \\
\text { nanceiros públicos para a manu- } \\
\text { tenção do cotidiano escolar, ga- } \\
\text { rantindo a plena participação de } \\
\text { cada comunidade indígena nas } \\
\text { decisões relativas ao funciona- } \\
\text { mento da escola. }\end{array}$ \\
\hline $\begin{array}{l}\text { Convenção } \\
\text { 169/OIT - } \\
\text { Decreto nº } \\
5.051 / 2004\end{array}$ & $\begin{array}{l}\text { Art. } 26 \text { - Deverão ser ado- } \\
\text { tadas medidas para garantir } \\
\text { aos membros dos povos em } \\
\text { questão a oportunidade de } \\
\text { receberem educação em to- } \\
\text { dos os níveis, ao menos em } \\
\text { condições de igualdade com } \\
\text { o restante da comunidade } \\
\text { nacional. }\end{array}$ & $\begin{array}{l}\text { Art. } 27 \text { - Os programas e os } \\
\text { serviços de educação desti- } \\
\text { nados a esses povos deve- } \\
\text { rão ser desenvolvidos e im- } \\
\text { plementados em cooperação } \\
\text { com eles, a fim de atender às } \\
\text { suas necessidades particula- } \\
\text { res, e deverão incorporar sua } \\
\text { história, seus conhecimentos } \\
\text { e técnicas, seus sistemas } \\
\text { de valores e todas as suas } \\
\text { demais aspirações sociais, } \\
\text { econômicas e culturais. }\end{array}$ & & \\
\hline $\begin{array}{l}\text { Decreto } \\
\text { Presiden- } \\
\text { cial } n^{0} 26 \\
\text { de } 1991\end{array}$ & $\begin{array}{l}\text { Atribui ao Ministério da Edu- } \\
\text { cação a competência para } \\
\text { integrar a educação escolar } \\
\text { indígena aos sistemas de } \\
\text { ensino regular. }\end{array}$ & & & \\
\hline $\begin{array}{l}\text { Decreto } n^{0} \\
1.904 \text { de } \\
1996\end{array}$ & $\begin{array}{l}\text { Instituiu o Programa Nacio- } \\
\text { nal de Direitos Humanos, } \\
\text { que estabelece a formula- } \\
\text { ção e implementação de po- } \\
\text { líticas de proteção e promo- } \\
\text { ção dos direitos indígenas. }\end{array}$ & & & \\
\hline
\end{tabular}

Fonte: elaboração dos autores com base em: Cenário Contemporâneo da Educação Escolar Indígena no Brasil (LUCIANO, 2007); Educação escolar indígena: diversidade sociocultural indígena ressignificando a escola (BRASIL, 2007); e Referencial Curricular Nacional para as Escolas Indígenas (BRASIL, 1998). 
Portanto, o direito à educação escolar indígena bilíngue, intercultural, específica, diferenciada e de gestão comunitária se deu em um campo de disputas políticas em direção ao processo de democratização do Brasil. Sendo assim, faz-se necessário pesquisar acerca dos direitos indígenas para conhecer as produções acadêmicas e traçar um panorama sobre o processo de implementação dos direitos garantidos nos marcos regulatórios.

Dessa maneira, este estudo caracteriza-se com uma revisão integrativa, objetivando analisar e sintetizar as teses e dissertações que versam sobre direitos indígenas e educação escolar, usando como plataforma de pesquisa o Banco de Dados de Teses e Dissertações ${ }^{2}$ do Instituto Brasileiro de Informação em Ciência e Tecnologia, do Ministério da Ciência, Tecnologia, Inovações e Comunicações, que reúne pesquisas acadêmicas de 107 instituições de ensino superior.

O estudo está estruturado da seguinte forma: primeiramente, explica-se a abordagem metodológica, revisão integrativa e seus processos. No segundo momento, apresentam-se os resultados do levantamento das teses e dissertações, seguido das análises e sínteses dos estudos selecionados. Por último, constam as considerações finais.

\section{Revisão integrativa e seus processos}

A revisão integrativa (RI) é uma abordagem metodológica para revisão de literatura que contribui para um amplo estudo sobre fenômenos teóricos e/ou empíricos, tornando-se, assim, uma alternativa para produzir o estado da arte de uma pesquisa científica. Um dos objetivos da RI é produzir uma ampla amostragem para gerar um panorama consistente e significativo sobre o fenômeno estudado (SOUZA; SILVA; CARVALHO, 2009).

Foram seguidas as etapas da RI com o intuito de manter os padrões do rigor metodológico propostos na abordagem. No primeiro passo, delimitaram-se as principais categorias do estudo (descritores): direitos humanos, direitos indígenas e educação escolar indígena. No segundo passo, iniciou-se o levantamento das teses e dissertações que trataram das categorias delimitadas, utilizando como plataforma de pesquisa o Banco de Dados de Teses e Dissertações (BDTD). Após o levantamento dos estudos, no terceiro passo, houve a seleção das teses e dissertações a partir das análises dos títulos, dos resumos e das considerações finais. $\mathrm{O}$ quarto e o quinto passos correspondem a apresentação, análise dos resultados e produção da síntese das teses e dissertações incluídas. 


\section{Resultados da pesquisa no BDTD}

Foram identificadas 74 teses e dissertações, de 24 universidades públicas e privadas do Brasil. Da amostragem, excluíram-se 62 estudos por três motivos: 1) os repositórios de teses e dissertações de algumas universidades - Universidade Federal da Grande Dourados (UFGD); Universidade do Oeste Paulista (UNOEST); Pontifícia Universidade Católica de Goiás (PUC/GO); Universidade Federal Rural de Pernambuco (UFRPE); Universidade Federal de Campina Grande (UFCG) - estavam com erro de conexão (EC), impossibilitando o acesso, a leitura e o download dos estudos, total de 10 trabalhos; 2) alguns estudos não correspondiam com as categorias delimitadas, discutindo a questão dos direitos humanos de forma ampla e não com o foco nos direitos indígenas, total de 48 trabalhos; 3) por duplicação de trabalhos no sistema, total de 4 trabalhos. Restaram, portanto, 12 teses e dissertações como amostragem, conforme o Quadro 2.

Quadro 2 - Repositórios consultados, universidades, quantitativos de referências e referências selecionadas por título e resumo - Belém, 2018

\begin{tabular}{|l|c|c|c|}
\hline \multicolumn{1}{|c|}{$\begin{array}{c}\text { Repositórios consultados das } \\
\text { universidades }\end{array}$} & $\begin{array}{c}\text { Quantitativo de } \\
\text { referências }\end{array}$ & $\begin{array}{c}\text { Referências selecionadas } \\
\text { por título e resumo }\end{array}$ & $\begin{array}{c}\text { № de teses e } \\
\text { dissertações }\end{array}$ \\
\hline Repositório da USP & 09 & 02 & T: 02 \\
\hline Repositório da Ufam & 08 & 02 & T: 02 \\
\hline Repositório da UnB & 07 & 01 & D: 01 \\
\hline Repositório da UFS & 05 & 01 & - \\
\hline Repositório da Famerp & 04 & 00 & T: 02 \\
\hline Repositório da UFGD & 04 & EC & - \\
\hline Repositório da PUCRS & 03 & 02 & D: 01 \\
\hline Repositório da PUC-SP & 03 & 00 & - \\
\hline Repositório da UFBA & 03 & 01 & - \\
\hline Repositório da UFG & 03 & 00 & D: 01 \\
\hline Repositório da UFSCar & 03 & 00 & - \\
\hline Repositório da Unisinos & 03 & 01 & - \\
\hline Repositório da Unoeste & 03 & EC & - \\
\hline Repositório da PUC Goiás & 02 & 00 & - \\
\hline Repositório da UEFS & 02 & 00 & D: 01 \\
\hline Repositório da Ufes & 02 & 00 & - \\
\hline Repositório da UFRPE & 02 & EC & - \\
\hline Repositório da Uninove & 02 & 01 & - \\
\hline Repositório da ESPM & 01 & 00 & D: 01 \\
\hline Repositório da UFCG & 01 & EC & - \\
\hline Repositório da UFJF & 01 & 00 & - \\
\hline Repositório da UFMT & 01 & 01 & 12 \\
\hline Repositório da Unesp & 01 & 00 & \\
\hline Repositório da Unigranrio & 01 & 00 & - \\
\hline Total & 74 & 12 & \\
\hline
\end{tabular}

Fonte: elaboração dos autores com base nos dados da pesquisa realizada em: 28/11/2018 no BDTD.

EC: erro de conexão; T: tese; D: dissertação. 
As teses e dissertações selecionadas apresentam características distintas. São estudos desenvolvidos em 6 programas de pós-graduação, são eles: Programa de Pós-Graduação em Educação - Ufam/UFMT/UFS/Uninove -, 4 estudos; Programa de Pós-Graduação em Direito - USP/UnB -, 3 estudos; Programa de Pós-Graduação em Serviço Social - PUCRS -, 2 estudos; Programa de Pós-Graduação Interdisciplinar Sociedade e Cultura na Amazônia - Ufam -, 1 estudo; Programa de Pós-Graduação em Antropologia Social - UFBA -, 1 estudo; e Programa de Pós-Graduação em Ciências Sociais - Unisinos -, 1 estudo. Todos os estudos compõem a grande área do conhecimento: Ciências Humanas e Sociais.

A maior parte dos estudos utilizaram como metodologia a pesquisa documental e bibliográfica, ou seja, 7 trabalhos (61\%), já aqueles que optaram pela pesquisa empírica, que envolvem seres humanos, somaram 5 estudos (59\%). Todos os estudos caracterizam-se como pesquisas qualitativas. Outra característica a ser destacada é que os estudos foram realizados entre os anos de 2008 a 2018, totalizando um recorte temporal de 10 anos de produção. Assim sendo, no Quadro 3, apresentam-se as teses e dissertações selecionadas para análise e produção do panorama geral sobre os direitos indígenas e educação escolar.

Quadro 3 - Teses e dissertações selecionadas para a análise - Belém, 2018

(continua...)

\begin{tabular}{|l|l|c|c|c|}
\hline \multicolumn{1}{|c|}{ Título } & \multicolumn{1}{|c|}{ Autores } & $\begin{array}{c}\text { Ano de } \\
\text { publicação }\end{array}$ & Universidade & $\begin{array}{c}\text { Tese / } \\
\text { Dissertação }\end{array}$ \\
\hline $\begin{array}{l}\text { A Universidade Federal do Amazonas e } \\
\text { o acesso dos povos indígenas ao ensino } \\
\text { superior. desafios da construção de uma } \\
\text { política institucional }\end{array}$ & $\begin{array}{l}\text { Rita Floramar } \\
\text { dos Santos Melo }\end{array}$ & 2008 & Ufam & Dissertação \\
\hline $\begin{array}{l}\text { Direito ao desenvolvimento de comunida- } \\
\text { des indígenas no Brasil }\end{array}$ & $\begin{array}{l}\text { Robério Nunes } \\
\text { dos Anjos Filho }\end{array}$ & 2009 & USP & Tese \\
\hline $\begin{array}{l}\text { As comunidades Quilombolas do campo } \\
\text { em Sergipe e os desafios da formação } \\
\text { docente }\end{array}$ & $\begin{array}{l}\text { Glezia Kelly } \\
\text { Costa Santos }\end{array}$ & 2011 & UFS & Dissertação \\
\hline $\begin{array}{l}\text { A educação em diretos humanos e o di- } \\
\text { reito dos povos indígenas: um estudo de } \\
\text { caso sobre o desenvolvimento e diversida- } \\
\text { de no Mato Grosso do Sul }\end{array}$ & $\begin{array}{l}\text { Ângela Apare- } \\
\text { cida da Cruz } \\
\text { Duran }\end{array}$ & 2013 & USP & Tese \\
\hline $\begin{array}{l}\text { Territorialidade e condições de vida dos } \\
\text { indígenas Cocama da Comunidade Nova } \\
\text { Esperança de Manaus/AM }\end{array}$ & $\begin{array}{l}\text { Roseane Gui- } \\
\text { marães Cabral } \\
\text { Costa }\end{array}$ & 2014 & Ufam & Dissertação \\
\hline
\end{tabular}


(conclusão)

\begin{tabular}{|l|l|l|l|l|}
\hline $\begin{array}{l}\text { (Re)Tomando a escola: reflexões sobre } \\
\text { educação escolar indígena entre os Pata- } \\
\text { xó Hãhãhãe }\end{array}$ & Ivan Dutra Belo & 2014 & UFBA & Dissertação \\
\hline $\begin{array}{l}\text { Escola Pública Mbyá Guarani Tekoa Porã: } \\
\text { entre a preservação e o aniquilamento cul- } \\
\text { tural }\end{array}$ & $\begin{array}{l}\text { Ana Paula da } \\
\text { Costa Krumel }\end{array}$ & 2014 & Unisinos & Dissertação \\
\hline $\begin{array}{l}\text { Os direitos dos povos indígenas à educa- } \\
\text { ção superior na América Latina: concep- } \\
\text { ções, controvérsias e propostas }\end{array}$ & $\begin{array}{l}\text { Soledad Bech } \\
\text { Gaivizzo }\end{array}$ & 2014 & PUCRS & Tese \\
\hline $\begin{array}{l}\text { Aprendizagens da Lei 11.645/08 na expe- } \\
\text { riência intercultural dos XII Jogos dos Po- } \\
\text { vos Indígenas em Cuiabá-MT }\end{array}$ & $\begin{array}{l}\text { Gerda Langman- } \\
\text { tel Eichholz }\end{array}$ & 2015 & UFMT & Dissertação \\
\hline $\begin{array}{l}\text { lgualdade como diversidade no direito à } \\
\text { educação: erradicando a discriminação ét- } \\
\text { nico-racial no sistema de ensino brasileiro }\end{array}$ & $\begin{array}{l}\text { Gianna Ales- } \\
\text { sandra Sanchez } \\
\text { Moretti }\end{array}$ & 2017 & UnB & Tese \\
\hline $\begin{array}{l}\text { Experiência escolar Kariri-Xocó: discrimi- } \\
\text { nação e preconceito }\end{array}$ & $\begin{array}{l}\text { Claudinei de Aro } \\
\text { Poço }\end{array}$ & 2018 & Uninove & Dissertação \\
\hline $\begin{array}{l}\text { A política de cotas na educação superior. } \\
\text { as (a)simetrias entre o acesso nas univer- } \\
\text { sidades federais e o desenvolvimento so- } \\
\text { cial brasileiro }\end{array}$ & Carolina Ritter & 2018 & PUCRS & Tese \\
\hline
\end{tabular}

Fonte: elaboração dos autores com base nos dados da pesquisa realizada em: 15/12/2018 no BDTD.

\section{Análises e discussões}

A análise das teses e dissertações levou em consideração a fundamentação teórica, os objetivos traçados e as categorias: educação escolar e direitos indígenas, a partir das quais as sínteses serão apresentadas.

O direito à educação escolar para os povos indígenas é tratado como um território social, no qual se produzem conhecimentos diversos e específicos que podem contribuir para a produção de condições objetivas para uma realidade mais justa e equânime. Para Gaivizzo (2014, p. 106), “[...] tais direitos são representativos, na medida em que servem também como indicadores para analisar o grau de sociabilidade alcançado entre o Estado e as sociedades indígenas". Nesse contexto, o direito à educação escolar indígena é garantido pelo Estado por meio de políticas públicas que são ações afirmativas e de reconhecimento das diferenças, orientando-se pelo princípio de justiça compensatória e redistributiva.

Ritter (2018, p. 196) explica que no Brasil só se tornaram possíveis tais direitos a partir "[...] das demandas e da pressão exercida pelos movimentos negros e indígenas, que vêm denunciando as desigualdades raciais no país”. Sabe-se que 
as reivindicações dos povos indígenas por uma educação escolar indígena se deram em um contexto de conflitos políticos, contrapondo-se ao modelo de educação eurocêntrico, patriarcal, colonial e cristocêntrico, que objetivava a "integração e humanização dos povos tradicionais”. Foram os movimentos indígenas que propuseram o giro do sentido da educação escolar indígena, e esse giro é uma amostra da resistência e da luta dos povos.

Com esse giro do sentido, a partir da década de 1970, foi possível identificar e acompanhar algumas experiências de escolarização que se aproximavam dos pilares que sustentariam a educação escolar indígena nos anos posteriores. Como é o caso do processo de escolarização dos Pataxó Hãhãhãe, habitantes da região sul da Bahia, que se "[...] apropriaram da instituição, que ainda permanece como instituição de fronteira [...] sendo um lugar de conflitos e negociações" (BELO, 2014, p. 132). Os Pataxó Hãhãhãe resistiram ao processo perverso de contato com a sociedade nacional, e nesse processo perceberam que uma das formas de exclusão foi o letramento na língua portuguesa. Assim, segundo Belo (2014, p. 132), “[...] a experiência de exclusão [...] os motivou a lutar pelo direito da escolarização". Para o povo em questão, a escola é vista como um projeto de resistência e luta contra uma cultura de preconceito e ignorância que autoriza o racismo e a violência estrutural, reconfigurando o processo de escolarização. Eles transformaram a escola em um espaço de valorização cultural, "[...] fizeram da escola um lugar de saber sobre a sua história de luta, um lugar de união" (BELO, 2014, p. 136).

Os Guarani Mbyá, do Rio Grande do Sul, BR-116, Km 335, também veem a escola como um projeto de "fortalecimento da identidade pessoal e social dos indígenas" (KRUMEL, 2014, p. 138). A partir do letramento em português e em guarani, com intuito de registrar os elementos socioculturais e históricos, fortaleceram os movimentos indígenas no processo de acompanhamento e proposição de políticas públicas para as demandas do seu povo.

Embora se considere que "[...] a palavra falada é mais do que uma ligação entre humanos e o sagrado, é a própria substância da divindade" (KRUMEL, 2014, p. 139), os Guarani Mbyá entenderam a importância da coexistência entre a oralidade e a escrita, mostrando que é possível a existência de uma escola que respeite a cosmologia, as concepções de mundo, ou seja, "anunciando possibilidades para outro fazer escolar" (KRUMEL, 2014, p. 139), fazer esse que pauta a "arte de viver", a lógica do povo Guarani Mbyá.

Já os Kariri-Xocó, habitantes do baixo São Francisco, Alagoas, concebem a escola como uma instituição cujo papel fundamental é a discussão sobre a questão da 
demarcação de terras indígenas. Para Poço (2018, p. 175), “[...] ainda permanecem quadros de hostilidades oriundos de suas relações com latifundiários e fazendeiros", sendo que tais conflitos resultam em etnocídios. Sendo assim, os Kariri-Xocó não estão isentos da perversidade da especulação do agronegócio e da grilagem.

Os conflitos pelas terras no baixo São Francisco constituem um dos motivos que levam os Kariri-Xocó a evadirem de suas aldeias, rumo às grandes cidades. $\mathrm{O}$ esvaziamento das terras indígenas é um dos objetivos do agronegócio, pois se torna mais simples a invasão das terras quando o povo está reduzido e desarticulado. Essa realidade não é específica aos Kariri-Xocó, é uma estratégia utilizada pela grande indústria para desarticular, desvalorizar e desestruturar os movimentos indígenas, e o detalhe é que geralmente esse processo é violento, legitimado pela bancada evangélica e ruralista do Congresso Nacional. Isso posto, Poço (2018, p. 177) afirma que a escola dos Kariri-Xocó contribui para eles "[...] resistirem à hegemonia imposta, à discriminação, ao preconceito e à invisibilidade social".

Eichholz (2015) destaca, nesse sentido, a Lei no 11.645, de março de 2008, que tornou obrigatório o estudo das histórias e culturas afro-brasileira e indígena nas escolas públicas e privadas. A referida lei foi direcionada para as escolas não indígenas, a fim de contribuir com a formação dos brasileiros acerca da diversidade sociocultural indígena e suas contribuições nas áreas social, ambiental, econômica e política, pertinentes à história do Brasil. Segundo Eichholz (2015, p. 119), “[...] a Lei foi fruto de lideranças dos povos negros e indígenas por sua cultura, tradição e espiritualidade, diferenciadas da sociedade envolvente". Em outras palavras, a Lei nำ11.645/2008 é mais um mecanismo para garantir que os povos indígenas ocupem e transitem nos espaços "comuns" da sociedade, sem abdicar dos elementos socioculturais, de suas histórias, dos seus valores, dos seus princípios e de suas identidades.

Nesse sentido, o trabalho educativo nas escolas públicas e privadas deverá estar alinhado às questões dos direitos humanos, para que haja a garantia da ampla divulgação das histórias e culturas afro-brasileira e indígena, objetivando a desconstrução de uma cultura homogênea, branca, eurocêntrica, para a produção de uma pluralidade cultural que se aproxime da complexidade sociocultural do povo brasileiro. Para isso, o Estado precisa, como afirma Duran (2013, p. 164), "[...] investir maciçamente na educação para os Direitos Humanos e organizar-se politicamente e juridicamente".

Acredita-se que a questão étnico-racial também deve ser pautada nas agendas dos movimentos indígenas e sociais, pois os índices de desigualdades socioeconômicas e educacionais no Brasil voltaram a crescer. O Brasil ocupa o $10^{\circ}$ lugar no ran- 
king dos países mais desiguais do mundo, segundo o Relatório de Desenvolvimento Humano (RDH), elaborado pela Organização das Nações Unidas (ONU) (2016). Segundo o RDH, a desigualdade social é apontada como um dos desafios que o Brasil precisa enfrentar, e sabe-se que o enfretamento se dá no campo político. Nesse sentido, "[...] as desigualdades são acentuadas ainda mais pelo fator étnico-racial, além do fator gênero e territorial" (MORETTI, 2017, p. 161).

Segundo Moretti (2017, p. 161), os indicadores sugerem que existem "[...] níveis de desigualdades sociais mais elevados entre os brasileiros autodeclarados negros em comparação com os autodeclarados brancos”. Entre os povos indígenas essa realidade não é diferente. Eles enfrentam cotidianamente inúmeros desafios pela persistência da discriminação, do racismo e do preconceito na sociedade envolvente, que influencia direta e intencionalmente a violação dos seus direitos garantidos na $\mathrm{CF} / 88$. Os desafios enfrentados pelos povos indígenas são fenômenos históricos, pois a cultura de exploração de grupos ou indivíduos rotulados como vulneráveis assola o presente e é legitimada pelo Congresso Nacional, reitera-se.

É consenso universal que as desigualdades sociais comprometem o processo de desenvolvimento humano. Ainda há a necessidade de humanizar as políticas públicas voltadas para as questões socioeconômicas e educacionais, para contribuir com ampliação e melhorias das condições de trabalho, saúde, segurança, etc., sobretudo para os povos indígenas, que ainda são marginalizados e taxados como um grupo social vulnerável.

Promover uma educação em ou para os direitos humanos é pensar novos paradigmas sociais, é reinventar processos sociais mais humanos, é lutar por justiça social, sem esquecer que a justiça social só será alcançada com a justiça cognitiva. Sendo assim, a educação escolar precisa dialogar com a diversidade de forma crítica, aprender com os povos indígenas como promover o giro de resistência e luta por uma sociedade verdadeiramente democrática, criando, assim, "[...] um ambiente favorável para a busca de soluções para superar as violências exacerbadas contra os povos indígenas" (DURAN, 2013, p. 166).

À vista disso, considera-se que as questões discutidas evidenciam os esforços dos povos indígenas pela dignidade humana que estão representados nos princípios que sustentam o direito constitucional indigenista, considerando o desejo genuíno de desconstruir o paradigma assimilacionista em prol da garantia do direito à alteridade e à diferença, sem esquecer também que o Estado deve preservar o princípio de reconhecimento e proteção às organizações sociais, aos costumes, às línguas, às crenças e às tradições dos povos indígenas (ANJOS FILHO, 2009). 


\section{Considerações finais}

Tendo em vista o objetivo de analisar e sintetizar as teses e dissertações sobre direitos indígenas e educação escolar, foram selecionadas 12 pesquisas. É possível considerar que a educação escolar e os direitos indígenas são questões dialéticas e tensionadas. O conflito político é axial na sociedade nacional, haja vista que o espectro da colonialidade está presente nas instituições sociais, ou seja, a lógica perversa da exploração e marginalização social dos não brancos é um fenômeno estrutural historicamente imposto e consolidado no país. É por essa razão que os movimentos indígenas são egrégios. Não existe educação escolar indígena sem movimentos indígenas. O movimento está imbricado com a educação, e por isso o movimento é educativo, é pedagógico, é formativo. O movimento é o modus operandi de resistência e de luta contra os retrocessos políticos que surgiram a partir do Golpe de Estado de 2016 e, sobretudo, contra as manobras imorais impostas e avigoradas pelo atual governo, a saber: $\mathrm{PEC} / 2015$, que propõe a alteração da Constituição para transferir ao Congresso o poder de decisão final sobre a questão de demarcação de terras indígenas, territórios Quilombolas e unidades de conservação no Brasil, impactando em todas as terras que estão no processo de reconhecimento e demarcação e possibilitando a ampliação do poderio do agronegócio.

Nessa perspectiva, a educação escolar gerida pelos sujeitos indígenas torna-se de fato um projeto étnico-político, visando atender às diversas necessidades dos povos, deixando de ser proposta externa que pouco contribuiu com o bem-estar e para o seu desenvolvimento, mas serviu para consolidar o processo de embranquecimento, alienação e controle.

$\mathrm{Na}$ ordem da colonização, além das implicações já discutidas, outra que se apresenta como resultado desse processo de substituição é o empobrecimento cultural do país, que é uma das marcas da colonização. Além de os povos indígenas serem obrigados a falarem apenas uma língua (o português) e de expressarem apenas uma cultura (a do colonizador), a colonização deixa como legado a perda de muitas línguas e culturas. Tratar do diverso, ainda nos dias de hoje, é um grande desafio para a educação escolar, que, além de ser eurocêntrica, pretende-se monolíngue e monocultural. Nesses desafios se encontram as escolas indígenas por todo o país, tendo que lidar com essas situações de fronteiras, o que tem possibilitado novas formas de organização da educação e dos direitos indígenas.

As experiências de educação escolar indígena apresentadas sugerem que, quando os sujeitos indígenas estão na vanguarda dos processos educativos, as rela- 
ções entre povos indígenas, Estado e sociedade civil se entrelaçam, possibilitando o trânsito e a ocupação nos espaços "comuns" da sociedade. A educação é direito garantido e se caracteriza como um território social, um ponto de contato interétnico estratégico.

Dessa forma, o direito à educação escolar é visto como um processo de instrumentalização política para que os sujeitos indígenas, a partir dos movimentos, possam se organizar enquanto coletivo, para continuar pressionando e cobrando o Estado para a garantia, ampliação, continuidade e aplicação dos direitos conquistados historicamente.

Cabe salientar que o direito indígena, segundo a CF/88 e a Lei nº 9.394/1996, tem como objeto os direitos à autodeterminação, à manutenção dos elementos socioculturais, à possibilidade de optar por um projeto de desenvolvimento social, à permanência e à vida no território indígena, ao usufruto dos recursos naturais nos territórios indígenas, ao desenvolvimento socioeconômico, à saúde, ao trabalho, à renda e à educação bilíngue/multilíngue, específica, diferenciada, intercultural e de gestão comunitária.

Assevera-se que o direito à educação deve ser apresentado como um direito fundamental na ordem constitucional, pois os direitos fundamentais, bem como os direitos humanos, representam um elenco de direitos garantidos na constituição, que reconhece a autonomia e o potencial dos povos indígenas em se organizar efetivamente como um ato de emancipação, sendo condição para a concretização e efetivação dos mecanismos legais.

Contudo, tais procedimentos legais só serão possíveis a partir dos movimentos indígenas, em um contínuo diálogo tensionado com a sociedade envolvente e com o Estado, que deve prover planejamento e implementação de políticas públicas que auxiliem os povos originários no processo de reconfiguração da educação escolar, tornando-a plural, diversa, dinâmica, respeitando a perspectiva de pertencimento e identitária de cada povo.

\section{Nota}

1 Ressalta-se que o movimento articulou uma rede de 1.156 professores indígenas que trabalharam com um universo de 25.902 alunos. Organizou-se em nove regiões: alto e médio Solimões, baixo Amazonas, alto, médio e baixo Madeira, Rio Negro (no Amazonas); Roraima e Acre. Participaram diretamente dos encontros anuais 390 professores de 32 povos.

2 A Biblioteca Digital Brasileira de Teses e Dissertações integra e dissemina, em um só portal de busca, os textos completos das teses e dissertações defendidas nas instituições brasileiras de ensino e pesquisa. Disponível em: www.bdtd.ibict.br. Acesso em: 28 nov. 2018. 


\section{Referências}

ANJOS FILHO, Robério Nunes dos. Direito ao desenvolvimento de comunidades indígenas no Brasil. Tese (Doutorado em Direito) - Faculdade de Direito do Largo São Francisco, Universidade de São Paulo, São Paulo, 2009.

BELO, Ivan Dutra. (Re)tomando a escola: reflexões sobre educação escolar indígena entre os Pataxó Hãhãhãe. Dissertação (Mestrado em Antropologia) - Faculdade de Filosofia e Ciências Humanas, Universidade Federal da Bahia, Salvador, 2014.

BRASIL. Constituição da República Federativa do Brasil (1934). Promulgada em 16 de julho de 1934. Disponível em: www.planalto.gov.br/ccivil_03/constituicao34.htm. Acesso em: 22 dez. 2018.

BRASIL. Constituição da República Federativa do Brasil (1946). Promulgada em 18 de setembro de 1946. Disponível em: www.planalto.gov.br/ccivil_03/constituicao46.htm. Acesso em: 22 dez. 2018.

BRASIL. Constituição da República Federativa do Brasil (1967). Promulgada em 24 de janeiro de 1967. Disponível em: www.planalto.gov.br/ccivil_03/constituicao67.htm. Acesso em: 22 dez. 2018.

BRASIL. Constituição da República Federativa do Brasil (1988). Promulgada em 05 de outubro de 1988. Disponível em: www.planalto.gov.br/ccivil_03/constituicao88.htm. Acesso em: 22 dez. 2018.

BRASIL. Decreto no 26. Promulgado em 04 de fevereiro de 1991. Disponível em: www.planalto. gov.br/ccivil_03/Decreto/1990-1994/D0026.htm. Acesso em: 22 dez. 2018.

BRASIL. Ministério da Educação. Lei no 9.394. Brasília, DF: Secretaria de Educação Fundamental, 1996.

BRASIL. Decreto n $\square$ 1.904. Promulgado em 13 de maio de 1996. Disponível em: http://www. planalto.gov.br/ccivil_03/decreto/D1904.htm. Acesso em: 22 dez. 2018.

BRASIL. Ministério da Educação. Referencial curricular nacional para as escolas indígenas. Brasília, DF: Secretaria de Educação Fundamental, 1998.

BRASIL. Lei nº 10.172/2001. Aprova o Plano Nacional de Educação e dá outras providências. Brasília, DF: Secretaria de Educação Fundamental, 2001.

BRASIL. Decreto no 5.051. Promulgado em 19 de abril de 2004. Disponível em: www.planalto. gov.br/ccivil_03/Ato2004-2006/2004/Decreto/D5051.htm. Acesso em: 22 dez. 2018.

BRASIL. Secretaria de Educação Continuada, Alfabetização e Diversidade. Educação escolar indigena: diversidade sociocultural indígena ressignificando a escola. Brasília, DF: Ministério da Educação, 2007.

COSTA, Roseane Guimarães Cabral. Territorialidade e condições de vida dos indígenas Cocama da comunidade Nova Esperança de Manaus, Amazonas. Dissertação (Mestrado em Sociedade e Cultura na Amazônia) - Instituto de Ciências Humanas e Letras, Universidade Federal do Amazonas, Manaus, 2014.

DURAN, Angela Aparecida da Cruz. A educação em direitos humanos e o direito dos povos indígenas: um estudo de caso sobre desenvolvimento e diversidade no Mato Grosso do Sul. Tese (Doutorado em Direito) - Faculdade de Direito do Largo São Francisco, Universidade de São Paulo, São Paulo, 2013. 
EICHHOLZ, Gerda Langmantel. Aprendizagens da Lei no 11.645 / 08 na experiência intercultural dos XII jogos dos Povos Indigenas em Cuiabá-MT. Dissertação (Mestrado em Educação) - Instituto de Educação, Universidade Federal de Mato Grosso, Cuiabá, 2015.

GAIVIZZO, Soledad Bech. O direito dos povos indígenas a educação superior na América Latina: concepções, controvérsias e propostas. Tese (Doutorado em Serviço Social) - Faculdade de Serviço Social, Pontifícia Universidade Católica do Rio Grande do Sul, Porto Alegre, 2014.

KRUMEL, Ana Paula da Costa. Escola pública Mbyá Tekoa Porã: entre a preservação e o aniquilamento cultural. Dissertação (Mestrado em Ciências Sociais) - Instituto de Ciências Sociais, Universidade do Vale do Rio dos Sinos, São Leopoldo, 2014.

LUCIANO, Gersem José dos Santos. Cenário contemporâneo da educação escolar indígena no Brasil. Brasília, DF: Ministério da Educação; Conselho Nacional de Educação; Câmara de Educação Básica, 2007.

MELO, Rita Floramar dos Santos. A Universidade Federal do Amazonas e o acesso dos povos indígenas ao ensino superior: desafios da construção de uma política institucional. Dissertação (Mestrado em Educação) - Faculdade de Educação, Universidade Federal do Amazonas, Manaus, 2008.

MORETTI, Gianna Alessandra Sanchez. Igualdade como diversidade no direito à educação: erradicando a discriminação étnico-racial no sistema de ensino brasileiro. Tese (Doutorado em Direito) - Faculdade de Direito, Universidade de Brasília, Brasília, 2017.

ONU. Relatório de desenvolvimento humano ( $R D H)$. Desenvolvimento humano para todos. 2016. Disponível em: https://www.undp.org/content/dam/angola/docs/documents/HDR2016\%20 2016\%20PT\%20ANGOLA.pdf. Acesso em: 14 dez. 2018.

ORGANIZAÇÃO INTERNACIONAL DO TRABALHO. Convenção $n^{\circ} 169$ sobre os povos indígenas e tribais e resolução referente à da OIT. Brasília, DF: OIT, 2011.

POÇO, Claudinei de Aro. Experiência escolar Kariri-Xocó: discriminação e preconceito. Dissertação (Mestrado em Educação) - Faculdade de Educação, Universidade Nove de Julho, São Paulo, 2018.

RITTER, Caroline. A política de cotas na educação superior: as (a)simetrias entre o acesso nas universidades federais e o desenvolvimento social brasileiro. Tese (Doutorado em Serviço Social) - Pontifícia Universidade Católica do Rio Grande do Sul, Porto Alegre, 2018.

SANTOS, Glezia Kelly Costa. As comunidades quilombolas do campo em Sergipe e os desafios da formação docente. Dissertação (Mestrado em Educação) - Faculdade de Educação, Universidade Federal de Sergipe, São Cristóvão, 2011.

SILVA, Rosa Helena. Autonomia como valor e articulação de possibilidades: o movimento dos professores indígenas do Amazonas, de Roraima e do Acre e a construção de uma política de educação escolar indígena. Cadernos Cedes, Campinas, ano XIX, n. 49, p. 62-75, dez. 1999.

SOUZA, Marcela Tavares de; SILVA, Michelly Dias da; CARVALHO, Rachel de. Revisão integrativa: o que é e como fazer? Einstein, São Paulo, n. 8, p. 102-106, jun. 2009. 